\section{Removal of a razor blade from the stomach with unusual accessory tools}

An 18-year-old male convict was brought to the emergency department upon stating that he had swallowed a foreign body the day before. He had no complaints, and no abnormality was observed on physical examination. Direct radiography revealed a foreign body in a gastric location. On gastroduodenoscopy, a razor blade measuring $4 \times 1 \mathrm{~cm}$ was observed at the larger curvature ( $\bullet$ Fig. 1 ). As there was no protection cap on the razor, which had sharp edges, the foreign body forceps was not used for removal. Instead, the razor blade was easily broken into pieces intragastrically using an endoscopic retrograde cholangiopancreatographic (ERCP) lithotripsy basket ( $\bullet$ Fig. 2 ), and was removed with the help of a band ligator cap connected to the endoscope ( $\bullet$ Fig. 3). No complication was observed. In the absence of accessory tools, an ERCP basket and band ligator cap allowed easy and safe removal of a sharp foreign body. Several methods have been described for the safe removal of foreign material with sharp edges [1,2]. The complications are related to the edges and the size of the foreign material [3]. The success rate of endoscopic removal of foreign bodies has increased with the use of accessory tools and has now been reported at 94\% [4].

Endoscopy_UCTN_Code_TTT_1AO_2AL

K. Dolay ${ }^{1}$, A. Soylu ${ }^{2}$, O. Z. Oner ${ }^{1}$, E. Aygun ${ }^{1}$

1 General Surgery Department Endoscopy Unit, Bakırköy Research and Training Hospital, Bakırköy, Istanbul, Turkey

2 Department of Gastroenterology, Bakırköy Research and Training Hospital, Istanbul, Turkey

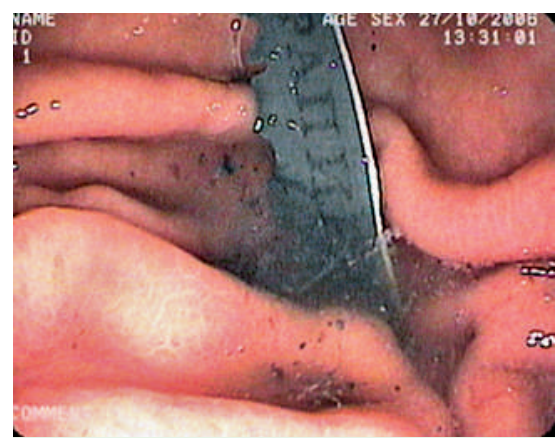

Fig. 1 Razor blade between the gastric plica on the larger curvature.

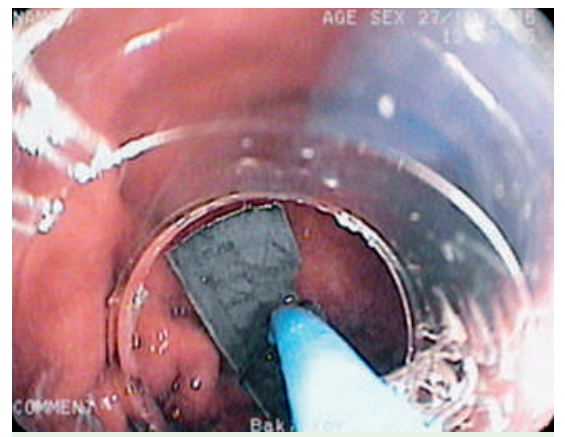

Fig. 2 Removal using lithotripsy basket and band ligator cap.

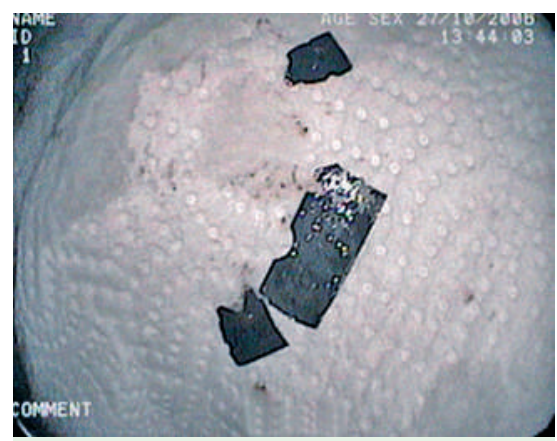

Figure 3 The foreign material removed from the patient's stomach.

\section{References}

1 Adler DG. Fast-food bolus nation. Gastrointest Endosc 2006; 64: 493-495

2 Karjoo M, A-Kader $H$. A novel technique for closing and removing an open safety pin from the stomach. Gastrointest Endosc 2003; 57: 627-629

3 Witzel L, Scheurer $U$ et al. Removal of razor blades from stomach with fiberoptic endoscope. Br Med J 1974; 2: 539

4 Li ZS, Sun ZX et al. Endoscopic management of foreign bodies in the upper-GI tract: experience with 1088 cases in China. Gastrointest Endosc 2006; 64: 485-492

Bibliography

DOI $10.1055 / \mathrm{s}-2007-966415$

Endoscopy 2007; 39: 255

(c) Georg Thieme Verlag KG Stuttgart · New York . ISSN 0013-726X

\section{Corresponding author}

\section{K. Dolay, MD}

Bakırköy Eğitim ve Araştırma Hastanesi

Genel Cerrahi Kliniği

Istanbul

Turkey

Fax: +90-212-5713278

dolayk@yahoo.com 